\title{
Evaluation of drug metabolism in Hispanic americans with type 2 diabetes
}

\author{
Thomas C. Dowling ${ }^{1 *}$, Magaly Rodriguez de Bittner ${ }^{1}$, Zhanita Perez ${ }^{1}$, Andrew Briglia ${ }^{3}$ and Ligia Peralta ${ }^{2}$ \\ *Correspondence: tdowling@rx.umaryland.edu \\ ${ }^{1}$ University of Maryland School of Pharmacy, Department of Pharmacy Practice and Science, Baltimore, Maryland. \\ ${ }^{2}$ University of Maryland School of Medicine, Baltimore, Maryland. \\ ${ }^{3}$ Annapolis Nephrology Associates, Annapolis, Maryland.
}

\begin{abstract}
Background: Type 2 diabetes mellitus (T2DM) is highly prevalent in the Latino population. Many antidiabetic drugs such as sulfonylureas, dipeptidylpeptidase- 4 inhibitors and pioglitizone, are metabolized in the liver by polymorphic cytochrome-P450 (CYP) enzymes including CYP2B6, CYP3A5, and CYP2C9. The prevalence of CYP allelic variants is largely unknown in Latino patients with T2DM. The objective of this study was to evaluate liver function and drug metabolism in a medically underserved population of Latino patients with T2DM.

Methods: This pilot study included 14 Latinos and 12 age-matched non-Hispanic controls. Genetic variants of CYP2B6, CYP3A5 and CYP2C9 were identified by polymerase chain reaction using TaqMan allelic discrimination. Hepatic CYP3A phenotype was measured by the erythromycin breath test (ERMBT). Kidney function was estimated by CLCr and GFR was measured by iothalamate clearance. The Shapiro-Wilk test was used to evaluate normality distribution, and between-group comparisons were made using either t-test or Mann-Whitney U.

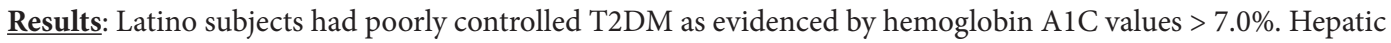
CYP3A phenotype, measured by ERMBT, was $22 \%$ lower than controls $(\mathrm{p}=0.047)$. The CYP3A5 3 splice variant was present in all subjects. In CYP3A $5^{\star} 1$ carriers, EBT values were slightly higher than those homozygous for the $* 3$ allele $(2.32 \pm 0.04 \%$ vs. $1.96 \pm 0.47 \%, \mathrm{p}=0.2)$. Seven out of 11 subjects $(64 \%)$ were homozygous for the CYP2B6 $6^{\star} 6$ allele, and 10 out of $11(91 \%)$ were carriers of the $2 \mathrm{~B}^{\star} 6$ allele. There were no subjects possessing the CYP $3 \mathrm{~A} 5^{\star} 6$ or CYP2C $9^{\star} 3$ alleles. Kidney function testing showed a mean urinary albumin-to-creatinine ratio (ACR) of $24 \pm 47 \mathrm{mg} / \mathrm{g}$ and measured GFR of $141 \pm 24 \mathrm{~mL} / \mathrm{min}$. Creatinine clearance was significantly higher in Latino subjects compared to controls $(145 \pm 33 \mathrm{~mL} / \mathrm{min}$ vs. $102 \pm 21 \mathrm{~mL} / \mathrm{min}, \mathrm{p}<0.001)$.

Conclusion: This evaluation of drug metabolism in Latino patients with diabetes identified polymorphic variants of CYP2B6 and CYP3A5 associated with reduced CYP enzyme activity in the presence of glomerular hyperfiltration. Further studies are needed to confirm these findings and to understand the implications in drug selection for Latino patients with T2DM.
\end{abstract}

Keywords: Kidney function, Glomerular filtration rate (GFR), Cytochrome P-450 (CYP), pharmacogenomics, Hispanic Americans, type 2 diabetes

\section{Background}

The prevalence of Type 2 diabetes (T2DM) in Hispanic Americans is approximately 1.5-3.0 times that reported in the non-Hispanic White population and its incidence is rising [1]. Diabetes is the leading cause of ESRD among Latinos who have a 6 -fold higher incidence of treatment for diabetic ESRD than non-Hispanic whites $[2,3]$. Pugh et al., reported that T2DM caused ESRD in $59.5 \%$ of nonHispanic whites and $92.8 \%$ of Mexican-Americans [2]. According to the United States Renal Data System (USRDS) in 2008, there were over 15,000 Hispanics newly diagnosed with ESRD, representing an increase of 78\% since 1996 [4]. Peralta et al., [5] examined the associations between Hispanic ethnicity and chronic kidney disease (CKD), risks for ESRD, cardiovascular events, and death. Among 39,550 patients with stages 3-4 CKD, Hispanics were at a higher risk for ESRD (hazard ratio [HR] 1.93; [CI] 1.72 to 2.17) when compared with non-Hispanic white patients. Furthermore, Latinos have the highest age-adjusted prevalence of metabolic syndrome (31.9\%) compared with non-Hispanic Whites (23.8\%) and Blacks (21.6\%), and Hispanics have been found to have lower rates of glucose self-monitoring and poorer glycemic control compared with non-Hispanic Whites [6]. Thus, identifying potential causes of treatment failure and progression of chronic kidney disease in Latinos with T2DM is of high research priority.

The prevalence of genetic variants of CYP enzymes in Latinos with T2DM is largely unknown. Limited studies in non-diabetic Mexican Americans have reported similar frequencies of CYP2D6, CYP3A and CYP2E1 genotypes 
Dowling et al. Journal of Diabetes Research \& Clinical Metabolism 2012, http://www.hoajonline.com/journals/pdf/2050-0866-1-22.pdf

Table 1. Characteristics of the Study Population ${ }^{\mathrm{a}}$

\begin{tabular}{|c|c|c|c|}
\hline Characteristic & $\begin{array}{c}\text { Hispanic } \\
\text { Cohort }(n=14)\end{array}$ & $\begin{array}{l}\text { Non-Hispanic } \\
\text { Controls }(n=12)\end{array}$ & p value \\
\hline $\operatorname{Age}(y r)^{b}$ & $45(11)$ & $47(7)$ & NS \\
\hline $\begin{array}{r}\text { Latin American Origin } \\
\text { Mexico } \\
\text { Central America } \\
\text { South America } \\
\text { Carribean }\end{array}$ & $\begin{array}{l}3 \\
4 \\
2 \\
5\end{array}$ & $\begin{array}{l}-- \\
-- \\
-- \\
--\end{array}$ & - \\
\hline Female/Male & $4 / 10$ & $6 / 6$ & NS \\
\hline Weight $(\mathrm{kg})$ & $80(13)$ & $72(17)$ & NS \\
\hline Body Surface Area $\left(\mathrm{m}^{2}\right)$ & $1.88(0.19)$ & $1.83(0.25)$ & NS \\
\hline Serum Creatinine (mg/dL) & $0.71(0.14)$ & $0.84(0.12)$ & 0.03 \\
\hline $\operatorname{CLcr}(\mathrm{mL} / \mathrm{min})$ & $145(33)$ & $102(21)$ & $<0.001$ \\
\hline Estimated GFR (mL/min) & $134(26)$ & $104(27)$ & 0.0146 \\
\hline Measured GFR (mL/min) & $141(24)$ & - & - \\
\hline Hemoglobin AlC (\%) & $9.1(3.1)$ & - & - \\
\hline $\begin{array}{l}\text { Urinary albumin:creatinine } \\
(\mathrm{ACR}, \mathrm{mcg} / \mathrm{mgC})\end{array}$ & $24(42)$ & - & - \\
\hline Blood glucose (fasting, mg/dL) & $188 \pm 74$ & - & - \\
\hline
\end{tabular}

${ }^{a} \mathrm{~N}=26$

${ }^{\mathrm{b} C o n t i n u o u s ~ d a t a}$ are presented as mean (SD).

and phenotypes compared to non-Hispanic whites $[7,8]$. Luo et al., reported a lower frequency of CYP2C19*2 and *3 genotypes but similar frequency of CYP2C19 poor metabolizer phenotype (as measured by S-mephenytoin 4'-hydroxylation) in Mexican Americans compared to nonHispanic whites [9]. Experimental data from human liver microsomes suggests that CYP2B6 activity is increased in liver tissue from Hispanic donors compared to African American and Caucasian donors [10], but in vivo studies of CYP2B6 metabolism in Latinos have not been reported. The present study examined the genotype characteristics of CYP2B6, CYP2C9, and CYP3A5, along with phenotype assessment of CYP3A and kidney function measurement in a cohort of Latinos with known or self-reported T2DM in the Baltimore metropolitan region.

\section{Methods}

The study groups consisted of self-reported Latin Americans with T2DM identified from ambulatory Hispanic Community Health Clinics and age-matched non-Hispanic controls. The clinical protocol was approved by University of Maryland IRB and the General Clinical Research Center (GCRC) Advisory Committee. All subjects received a history and physical examination in the GCRC including serum and urine biochemistry evaluations with confirmation of T2DM based on fasting blood glucose. Subjects were excluded if they had active or a history of liver disease or were receiving medications known to alter hepatic CYP3A enzyme activity. The data from non-diabetic, non-Hispanic, non-CKD patients was obtained from a previous study evaluating CYP3A-mediated drug metabolism in patients with end-stage renal disease [11]. Glomerular filtration rate (GFR) was measured during a single visit to the GCRC using non-radioactive iothalamate clearance, and iothalamate concentrations were determined by HPLC as previously described [12]. Urinary albumin-to-creatinine ratios (ACR) were determine from a spot urine collection at the time of admission to the GCRC. lothalamate pharmacokinetic data was analyzed using WinNonlin 5.2 (Cary, NC). Hepatic CYP3A-mediated metabolism was assessed in the University of Maryland Medical Center's Department of Radiology using the Erythromycin Breath Test (Metabolic Solutions, Inc., Nashua, $\mathrm{NH}$ ), where \% of erythromycin dose eliminated per hour was determined in a single breath sample obtained 20 minutes following a $3 \mu \mathrm{Ci}$ injection of $\mathrm{C} 14$-erythromycin (ERMBT $E_{20 \mathrm{~min}}$ ). The ERMBT $E_{20 \mathrm{~min}}$ test measures the extent of hepatic N-demethylation of erythromycin, which is known to be mediated by CYP3A, based on recovery of exhaled C14-erythromycin Genomic DNA was obtained from whole blood to identify the following SNPs: CYP2B6*6 (rs3745274), CYP3A5*3 (rs776746), CYP3A5*6 (rs10264272), CYP2C9*3 (rs1057910). Allelic discrimination was determined by rtPCR/TaqMan ${ }^{\oplus}$ using an ABI Prism 7900 HT Sequence Detection system (ABI Life Technologies Corp., Carlsbad, CA) with SDS software in the UM Biopolymer/Genomics Core Lab. Serum creatinine concentrations were determined using CREm calibrators (IDMS-traceable) on a Beckman Coulter UniCel DxC-800 (Beckman Coulter Inc., function was estimated using the Cockcroft-Gault (CG-CLcr) [13] and MDRD (IDMS traceable) [14] equations and reported in $\mathrm{mL} / \mathrm{min}$. Statistical analysis included linear regression, $t$-test and Mann-Whitney $U$ for continuous variables and chi-square or Fisher's exact test for nominal or categorical data using Prism 4.0 (GraphPad Software, Inc., LaJolla, CA).

\section{Results}

This was a single-center pilot evaluation of kidney and liver function conducted in an ambulatory care setting. The demographics of the 14 Latino and 12 control subjects are shown in Table 1. Genomic DNA was available in 11 of 14 Latino subjects. The hemoglobin A1C values were $>7.0 \%$ in 10 out of 14 subjects. Seven subjects were receiving metformin or glipizide at the time of evaluation, and no subjects were receiving insulin. The mean urinary albuminto-creatinine ratio (ACR) was $24 \mathrm{mg} / \mathrm{g}$, with 3 subjects having urinary ACR $>50 \mathrm{mg} / \mathrm{g}$. The iothalamate-measured GFR in Latino subjects was $141 \pm 24 \mathrm{~mL} / \mathrm{min}$, and estimated GFR values (using the MDRD equation) were significantly higher in Latinos vs. controls $(134 \pm 26 \mathrm{~mL} / \mathrm{min}$ vs. $104 \pm 27$ $\mathrm{mL} / \mathrm{min}, \mathrm{p}=0.01)$. Similarly, the estimated $\mathrm{CLcr}$ values were significantly higher in Latino subjects compared to controls (145 $\pm 33 \mathrm{~mL} / \mathrm{min}$ vs. $102 \pm 21 \mathrm{~mL} / \mathrm{min}, \mathrm{p}<0.001)$. In Latino subjects, the eGFR values were marginally greater than $\mathrm{CLCr}$ (134 $\pm 26 \mathrm{~mL} / \mathrm{min}$ vs. $128 \pm 31 \mathrm{~mL} / \mathrm{min}, \mathrm{p}=0.49)$ and were strongly associated with $\mathrm{CLCr}\left(\mathrm{r}^{2}=0.61, \mathrm{p}=0.001\right.$, Figure 1$)$. The mean ERMBT $E_{20 \text { min }}$ parameter value in Latinos was 


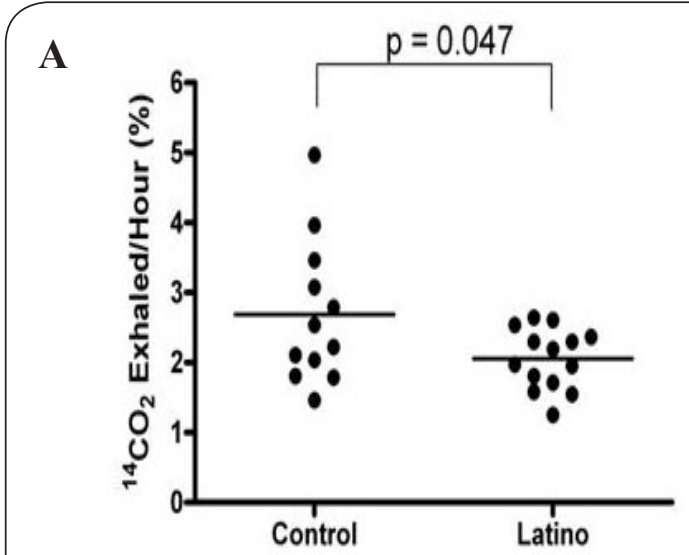

B

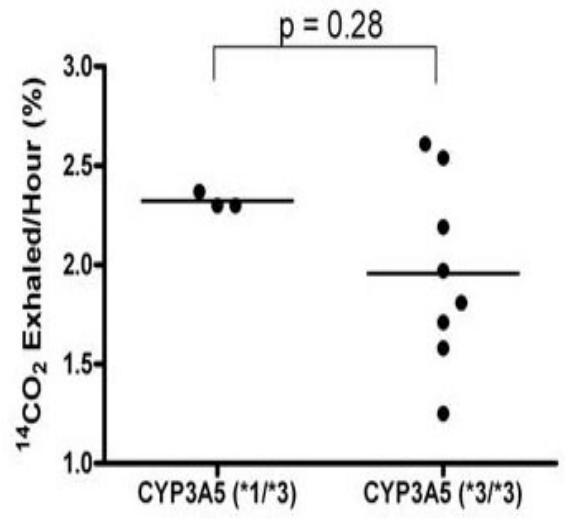

Figure 1. Results of CYP3A phenotype measured by Erythromycin Breath Test (ERMBT).

Panel A shows ERMBT values in Latino subjects compared to historical controls. Panel B shows ERMBT values in Latino subjects with CYP $3 \mathrm{~A} 5^{\star} 11^{\star} 3$ genotype (Expressors, $\mathrm{n}=3$ ) vs. CYP $3 A 5^{\star} 3 /^{\star} 3$ genotype (Non-Expressors, $n=8, p=0.237$ ).

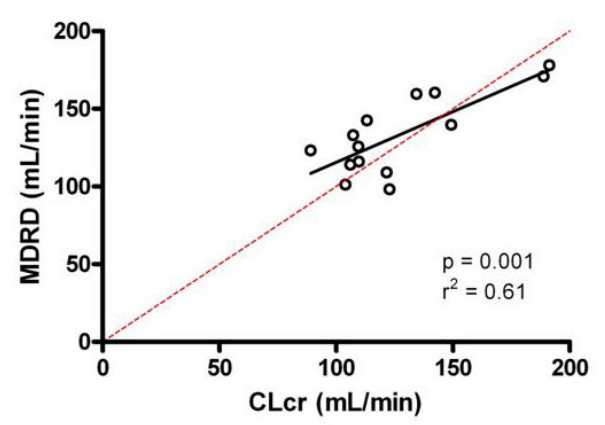

Figure 2. Relationship between estimated GFR and creatinine clearance in Latinos with T2DM. [-----] indicates line of identity.
$2.06 \pm 0.43 \%$, which was significantly lower than historical controls $(2.68 \% \pm 1.0 \%, p<0.05$, Figure 2$)$. The CYP3A5*3 splice variant was present in all subjects. In individuals that were CYP3A5* 1 allele carriers, ERMBT $E_{20 \mathrm{~min}}$ values tended to be slightly higher than those homozygous for the *3 allele $(2.32 \pm 0.04 \%$ vs. $1.96 \pm 0.47 \%, p=0.2)$. Seven out of 11 subjects (64\%) were homozygous for the CYP2B6*6 allele, and 10 out of 11 (91\%) were carriers of the CYP2B6* 6 allele. Hardy-Weinberg equilibrium comparisons between Latino and control groups could not be determined due to lack of genotyping availability in the control group. There were no subjects possessing the CYP3A5 $5^{*} 6$ or CYP2C $9^{*} 3$ alleles.

\section{Discussion}

The Latino subjects enrolled in this pilot study had poorly controlled diabetes in the presence of a minimal degree of nephropathy, as evidenced by elevated $\mathrm{HgA1C}(9 \pm 3 \%)$, low urinary albumin-to-creatinine ratio ( $24 \pm 41 \mathrm{mg} / \mathrm{g}$ ) and high measured GFR (141 $\pm 24 \mathrm{~mL} / \mathrm{min})$. This is the first study that we are aware of demonstrating glomerular hyperfiltration by measured GFR in Hispanic Americans with diabetes. Kidney function estimated by both CGCLCr and MDRD was higher than age-matched controls, suggesting an association between diabetes and glomerular hyperfiltration. Experimental and clinical evidence has shown that elevated GFR, or hyperfiltration, may increase the susceptibility to kidney injury in T2DM $[15,16]$.The degree of glomerular hyperfiltration observed in the present study is likely due to intraglomerular hypertension associated with early diabetes and known to be a precursor for albuminuria and subsequent reduction in GFR.

We also compared 2 equations used to estimate GFR (MDRD equation) and CLcr (CG equation) in the study population. Our finding that the MDRD values exceeded CG$\mathrm{CLCr}$ values in both Latinos and controls is consistent with previous studies in over 20,000 patients reporting that the MDRD equation overestimates creatinine clearance.[17,18] Each index of kidney function that we assessed (MDRD, CLcr and measured GFR) was consistent with hyperfiltration and early stage type 2 diabetes, although accurate histories of diabetes onset in the study subjects were compromised by limited access to care and medical documentation. Only 3 out of $14(21 \%)$ subjects in our study presented with microalbuminuria defined as urine ACR $30-300 \mathrm{mg} / \mathrm{g}$. This is consistent with data reported by the National Kidney Foundation's Kidney Early Evaluation Program (KEEP), where Hispanics with hypertension or diabetes (odds ratio [OR] 1.18, [CI] 0.87-1.60) were significantly less likely than African Americans (OR 1.46, [CI] 1.27-1.68) to present with microalbuminuria (measured by urine dipstick) during screening examinations [19]. Taken together, these data suggest that early diagnosis of diabetic nephropathy using sensitive measures such as urinary ACR and use of the MDRD equation should be avoided in this ethnic group exhibiting glomerular hyperfiltration. 
This is the first study to characterize CYP2B6, CYP2C9 and CYP3A5 genotype and phenotype in Latinos with diabetes. Our most striking finding was that $64 \%$ of our subjects were homozygous for the CYP2B6 ${ }^{*} 6(516 \mathrm{G} \rightarrow \mathrm{T}$ ) allele, which is markedly higher than previous reports of 6-24\% in Caucasians $[\mathbf{2 0 , 2 1 ]}$. Furthermore, nearly all (91\%) of our subjects carried a single copy of the CYP2B $6^{*} 6$ allele. This finding has important implications since this SNP is associated with impaired CYP-mediated metabolism of drugs such as methadone and efavirenz $[21,22]$. Ribaudo et al., [23] reported that the CYP2B6*6 $(516 \mathrm{G} \rightarrow \mathrm{T})$ polymorphism was present in $32 \%$ of Hispanics vs. $24 \%$ of Caucasian $(p<0.008)$ enrolled in an AIDS Clinical Trial. In contrast, Parkinson et al., [10]. reported that human hepatocytes obtained from Hispanic donors ( $n=10$ ) had CYP2B6-mediated $\mathrm{S}$-mephenytion $\mathrm{N}$-demethlylation that was nearly 2 -fold higher than African American ( $n=10)$ and Caucasian $(n=95)$ donors, but this difference was not statistically different due to considerable inter-subject variability.

We also observed that the CYP $3 A 5^{*} 3$ splice variant was present in all Latino subjects, which is similar to the 8595\% frequency reported in Caucasians and higher than the $27-55 \%$ frequency observed in African Americans $[24,25]$. Three subjects were carriers of the CYPBA5*1 allele, and these individuals tended to have higher values for ERMBT $\mathrm{E}_{20 \text { min }}$ compared to those not having the allele. This observation is consistent with prior reports showing increased clearance and higher dose requirements for tacrolimus in CYP3A5 "expressors" $\left({ }^{*} 1 /{ }^{*} 1\right.$ and $\left.{ }^{*} 1 /{ }^{*} 3\right)$ compared to CYP3A5 "non-expressors" $(* 3 / * 3)[26,27]$. Only one of our subjects possessed the CYP3A5*6 allele, which is associated with reduced CYP3A5 expression occurring more frequently in African Americans (2-17\%) compared with Caucasians and Asians (<2\%) [28].

Hepatic metabolic capacity measured by the ERMBT $\mathrm{E}_{20 \mathrm{~min}}$ was approximately $22 \%$ lower in Latino subjects compared to historical controls $(p<0.05)$. This finding suggests that Hispanic ethnicity may be associated with either reduced CYP3A-mediated hepatic metabolism or reduced hepatocellular drug uptake, since erythromycin metabolism likely requires initial uptake into hepatocytes mediated by solute transporters such as P-glycoprotein [31] The ERMBT has been widely used as a CYP3A phenotype probe in clinical trials to evaluate the impact of drugs and disease-states on CYP activity, enzyme induction, and inhibition $[11,29,30]$. The impact of Hispanic ethnicity on expression or function of hepatic drug transporters has not been previously reported. None of our subjects possessed the CYP2C9*3 $(A>C)$ allele, which is been reported as the second most frequent CYP2C9 SNP occurring in $5.4 \%$ of a Puerto Rican population [32]. This allele is associated with an allozyme that is considered "highly deficient" yielding a null metabolizer phenotype that has less than $5 \%$ metabolic activity and is most often included in warfarin genotyping algorithms [33].
Our pilot study was too small to make firm inferences about the frequency of CYP variant alleles in the general Latino population. Moreover, since we evaluated only 4 SNPS on 3 CYP enzymes, we were limited to evaluating the relationship between genotype and phenotype for CYP3A. Another limitation of our study is the possibility that the high GFR values observed in our Latino cohort may have been due to non-diabetic factors. Since our control group consisted of African American and Caucasians without kidney disease, their GFR values estimated by the MDRD equation, which takes race into account, may have underestimated the true GFR values.

\section{Conclusions}

The main findings in this pilot study are that Latino patients with T2DM have glomerular hyperfiltration with polymorphic variants of CYP2B6 and CYP3A5 that are associated with reduced CYP enzyme activity. These findings highlight the importance of early identification and utilization of a multidisciplinary team using a culturally sensitive approach in clinical settings to recognize drug-related problems and to maximize benefits in the Latino population with diabetes. Additional long-term studies are needed to further understand the clinical relevance of pharmacogenomics variants and their role in drug therapy individualization for Latino patients with diabetes.

\section{Competing interests}

The authors report no conflicts of interest or competing interests.

\section{Authors' contributions}

TD conceived of the study, and participated in its design and coordination and helped to draft the manuscript. MRB and ZP helped to coordinate the study and enroll study subjects. $A B$ and LP contributed to the evaluation of study subjects and interpretation of results. All authors read and approved the final manuscript.

\section{Acknowledgements and funding}

This study was funded in part by the American College of Clinical Pharmacy (Amgen Nephrology Research

Award, Frontier's Award); University of Maryland General Clinical Research Center grant (NIH M01 RR 16500).

\section{Publication history}

Received: 12-Nov-2012 Revised:11-Dec-2012

Accepted: 14-Dec-2012 Published: 21-Dec-2012

\section{References}

1. C. M. Lora, M. L. Daviglus, J. W. Kusek, A. Porter, A. C. Ricardo, A. S. Go and J. P. Lash: Chronic kidney disease in United States Hispanics: a growing public health problem. Ethn Dis 2009, 19:466-72. | PubMed

2. J. A. Pugh, R. A. Medina, J. C. Cornell and S. Basu: NIDDM is the major cause of diabetic end-stage renal disease. More evidence from a tri-ethnic community. Diabetes 1995, 44:1375-80. | Article | PubMed

3. I. Chukwueke and Z. Cordero-Macintyre: Overview of type $\mathbf{2}$ diabetes in Hispanic Americans. Int J Body Compos Res 2010, 8:77-81. | PubMed Abstract | PubMed Full Text

4. U.S. Renal Data System, USRDS 2010 Annual Data Report: Atlas of End-Stage Renal Disease in the United States, National Institutes 
of Health, National Institute of Diabetes and Digestive and Kidney Diseases, Bethesda, MD, 2010. | PDF

5. C. A. Peralta, M. G. Shlipak, D. Fan, J. Ordonez, J. P. Lash, G. M. Chertow and A. S. Go: Risks for end-stage renal disease, cardiovascular events, and death in Hispanic versus non-Hispanic white adults with chronic kidney disease. J Am Soc Nephrol 2006, 17:2892-9. | Article | PubMed

6. J. P. Burke, K. Williams, S. P. Gaskill, H. P. Hazuda, S. M. Haffner and M. P. Stern: Rapid rise in the incidence of type 2 diabetes from 1987 to 1996: results from the San Antonio Heart Study. Arch Intern Med 1999, 159:1450-6. | Article | PubMed

7. R. A. Poland, K. M. Lin, C. Nuccio and G. R. Wilkinson: Cytochrome P450 2E1 and 3A activities do not differ between Mexicans and European Americans. Clin Pharmacol Ther 2002, 72:288-93. | Article I PubMed

8. P. R. Casner: The effect of CYP2D6 polymorphisms on dextromethorphan metabolism in Mexican Americans. J Clin Pharmacol 2005, 45:1230-5. | Article | PubMed

9. H. R. Luo, R. E. Poland, K. M. Lin and Y. J. Wan: Genetic polymorphism of cytochrome P450 2C19 in Mexican Americans: a cross-ethnic comparative study. Clin Pharmacol Ther 2006, 80:33-40. | Article | PubMed

10. A. Parkinson, D. R. Mudra, C. Johnson, A. Dwyer and K. M. Carroll: The effects of gender, age, ethnicity, and liver cirrhosis on cytochrome P450 enzyme activity in human liver microsomes and inducibility in cultured human hepatocytes. Toxicol Appl Pharmacol 2004, 199:193209. | Article | PubMed

11. T. C. Dowling, A. E. Briglia, J. C. Fink, D. S. Hanes, P. D. Light, L. Stackiewicz, C. S. Karyekar, N. D. Eddington, M. R. Weir and W. L. Henrich: Characterization of hepatic cytochrome p4503A activity in patients with end-stage renal disease. Clin Pharmacol Ther 2003, 73:427-34. | Article | PubMed

12. T. C. Dowling, R. F. Frye and M. A. Zemaitis: Simultaneous determination of p-aminohippuric acid, acetyl-p-aminohippuric acid and iothalamate in human plasma and urine by high-performance liquid chromatography. J Chromatogr B Biomed Sci Appl 1998, 716:305-13. | Article | PubMed

13. D. W. Cockcroft and M. H. Gault: Prediction of creatinine clearance from serum creatinine. Nephron 1976, 16:31-41. | Article | PubMed

14. A. S. Levey, J. Coresh, T. Greene, J. Marsh, L. A. Stevens, J. W. Kusek and F. Van Lente: Expressing the Modification of Diet in Renal Disease Study equation for estimating glomerular filtration rate with standardized serum creatinine values. Clin Chem 2007, 53:766-72. | Article | PubMed

15. K. A. Griffin, M. Abu-Naser, I. Abu-Amarah, M. Picken, G. A. Williamson and A. K. Bidani: Dynamic blood pressure load and nephropathy in the ZSF1 ( $\mathrm{fa} / \mathrm{fa} \mathrm{cp}$ ) model of type 2 diabetes. Am J Physiol Renal Physiol 2007, 293:F1605-13. | Article | PubMed

16. G. M. Magee, R. W. Bilous, C. R. Cardwell, S. J. Hunter, F. Kee and D. G. Fogarty: Is hyperfiltration associated with the future risk of developing diabetic nephropathy? A meta-analysis. Diabetologia 2009, 52:691-7. | Article | PubMed

17. W. J. Spruill, W. E. Wade and H. H. Cobb, 3rd: Comparison of estimated glomerular filtration rate with estimated creatinine clearance in the dosing of drugs requiring adjustments in elderly patients with declining renal function. Am J Geriatr Pharmacother 2008, 6:153-60. | Article | PubMed

18. C. Melloni, E. D. Peterson, A. Y. Chen, L. A. Szczech, L. K. Newby, R. A. Harrington, W. B. Gibler, E. M. Ohman, S. A. Spinler, M. T. Roe and K. P. Alexander: Cockcroft-Gault versus modification of diet in renal disease: importance of glomerular filtration rate formula for classification of chronic kidney disease in patients with non-STsegment elevation acute coronary syndromes. J Am Coll Cardiol 2008, 51:991-6. | Article | PubMed

19. W. W. Brown, R. M. Peters, S. E. Ohmit, W. F. Keane, A. Collins, S. C. Chen, K. King, M. J. Klag, D. A. Molony and J. M. Flack: Early detection of kidney disease in community settings: the Kidney Early Evaluation Program (KEEP). Am J Kidney Dis 2003, 42:22-35. | Article | PubMed

20. M. Rohrbacher, A. Kirchhof, G. Geisslinger and J. Lotsch: Pyrosequencing-based screening for genetic polymorphisms in cytochrome P450 2B6 of potential clinical relevance. Pharmacogenomics 2006, 7:995-1002. | Article | PubMed

21. H. Bunten, W. J. Liang, D. J. Pounder, C. Seneviratne and D. Osselton: OPRM1 and CYP2B6 gene variants as risk factors in methadonerelated deaths. Clin Pharmacol Ther 2010, 88:383-9. | Article | PubMed

22. H. Gatanaga, T. Hayashida, K. Tsuchiya, M. Yoshino, T. Kuwahara, H. Tsukada, K. Fujimoto, I. Sato, M. Ueda, M. Horiba, M. Hamaguchi, M. Yamamoto, N. Takata, A. Kimura, T. Koike, F. Gejyo, S. Matsushita, T. Shirasaka, S. Kimura and S. Oka: Successful efavirenz dose reduction in HIV type 1-infected individuals with cytochrome P450 2B6 *6 and *26. Clin Infect Dis 2007, 45:1230-7. | Article | PubMed

23. H. J. Ribaudo, H. Liu, M. Schwab, E. Schaeffeler, M. Eichelbaum, A. A. Motsinger-Reif, M. D. Ritchie, U. M. Zanger, E. P. Acosta, G. D. Morse, R. M. Gulick, G. K. Robbins, D. Clifford and D. W. Haas: Effect of CYP2B6, ABCB1, and CYP3A5 polymorphisms on efavirenz pharmacokinetics and treatment response: an AIDS Clinical Trials Group study. J Infect Dis 2010, 202:717-22. | Article | PubMed Abstract | PubMed Full Text

24. H. G. Xie, A. J. Wood, R. B. Kim, C. M. Stein and G. R. Wilkinson: Genetic variability in CYP3A5 and its possible consequences. Pharmacogenomics 2004, 5:243-72. | Article | PubMed

25. J. K. Lamba, Y. S. Lin, E. G. Schuetz and K. E. Thummel: Genetic contribution to variable human CYP3A-mediated metabolism. Adv Drug Deliv Rev 2002, 54:1271-94. | Article | PubMed

26. F. Glowacki, A. Lionet, J. P. Hammelin, M. Labalette, F. Provot, M. Hazzan, F. Broly, C. Noel and C. Cauffiez: Influence of cytochrome P450 3 A5 (CYP3A5) genetic polymorphism on the pharmacokinetics of the prolonged-release, once-daily formulation of tacrolimus in stable renal transplant recipients. Clin Pharmacokinet 2011, 50:4519. | Article | PubMed

27. L. Renders, M. Frisman, M. Ufer, I. Mosyagin, S. Haenisch, U. Ott, A. Caliebe, M. Dechant, F. Braun, U. Kunzendorf and I. Cascorbi: CYP3A5 genotype markedly influences the pharmacokinetics of tacrolimus and sirolimus in kidney transplant recipients. Clin Pharmacol Ther 2007, 81:228-34. | Article | PubMed

28. D. Kurnik, A. J. Wood and G. R. Wilkinson: The erythromycin breath test reflects P-glycoprotein function independently of cytochrome P450 3A activity. Clin Pharmacol Ther 2006, 80:228-34. | Article | PubMed

29. T. D. Nolin, K. Appiah, S. A. Kendrick, P. Le, E. McMonagle and J. Himmelfarb: Hemodialysis acutely improves hepatic CYP3A4 metabolic activity. J Am Soc Nephrol 2006, 17:2363-7. | Article | PubMed

30. R. M. Franke, M. A. Carducci, M. A. Rudek, S. D. Baker and A. Sparreboom: Castration-dependent pharmacokinetics of docetaxel in patients with prostate cancer. J Clin Oncol 2010, 28:4562-7. | Article | PubMed Abstract | PubMed Full Text

31. D. Kurnik, A. J. Wood and G. R. Wilkinson: The erythromycin breath test reflects P-glycoprotein function independently of cytochrome P450 3A activity. Clin Pharmacol Ther 2006, 80:228-34. | Article | PubMed

32. J. Duconge, C. L. Cadilla, A. Windemuth, M. Kocherla, K. Gorowski, R. L. Seip, K. Bogaard, J. Y. Renta, P. Piovanetti, D. D’Agostino, P. J. Santiago-Borrero and G. Ruano: Prevalence of combinatorial CYP2C9 and VKORC1 genotypes in Puerto Ricans: implications for warfarin management in Hispanics. Ethn Dis 2009, 19:390-5. | PubMed Abstract | PubMed Full Text

33. B. F. Gage and L. J. Lesko: Pharmacogenetics of warfarin: regulatory, scientific, and clinical issues. J Thromb Thrombolysis 2008, 25:45-51. | Article | PubMed 